\title{
A transgenic in vitro cell model for the analysis of proinflammatory effects of naturally occurring genetic variants of caspase-1
}

\author{
F Schulze*, E Hengst, S Winkler, A Rösen-Wolff
}

From 8th International Congress of Familial Mediterranean Fever and Systemic Autoinflammatory Diseases Dresden, Germany. 30 September - 3 October 2015

\begin{abstract}
Introduction
Caspase-1 (Interleukin-1 Converting Enzyme, ICE) is a proinflammatory enzyme mediating cleavage and secretion of the proinflammatory cytokines IL- $1 \beta$ and IL- 18 . Caspase-1 plays pivotal roles in the innate immune system and in inflammatory diseases like periodic fever syndromes, arthritis, or type-II-diabetes. In previous studies published by our group, genetic variants of procaspase-1 had been detected in patients suffering from autoinflammatory symptoms. Analyses of the procaspase- 1 variants in HEK293T cells revealed reduced enzymatic activity of caspase- 1 but enhanced ability to activate NF- $\kappa$ B signaling. The latter was mediated by enhanced CARD/CARD interactions of procaspase-1 with RIP2.
\end{abstract}

\section{Objectives}

The primary objective of this study was to analyze the effects of procaspase-1 variants in a monocyte/macrophage cell model. Furthermore, protein expression and enzymatic activity of procaspase-1 with or without a C-terminal FLAG-tag was analyzed.

\section{Materials and methods}

Genetically engineered THP-1 monocytes were used for the in vitro study. First, THP-1 cells were transduced with lentiviral vectors expressing shRNA against procaspase-1 mRNA. Subsequently, procaspase-1 wildtype (wt) or variants with or without a C-terminal FLAG-tag were reconstituted using a second lentiviral transduction. THP-1 cells were differentiated into macrophages and stimulated with different inflammasome activators. Activation and release of caspase- 1 and IL- $1 \beta$ was assessed

\footnotetext{
University Hospital Carl Gustav Carus, Department of Pediatrics, Dresden,
} Germany

\section{Conclusion}

This study shows that even short protein-tags can influence protein expression significantly. Therefore, phenotypic rescue in knockdown studies can be complicated when using tagged proteins. Using the genetically engineered THP- 1 cells we were able to show a reduced IL- $1 \beta$ release and reduced frequency of pyroptosis following inflammasome stimulation without detecting any differential regulation of the proinflammatory cytokines IL-6 or IL-8. 
This study was supported by the German Research Foundation (DFG, KFO 249) and by a MeDDrive project (University of Technology, Medical Faculty) to SW.

Published: 28 September 2015

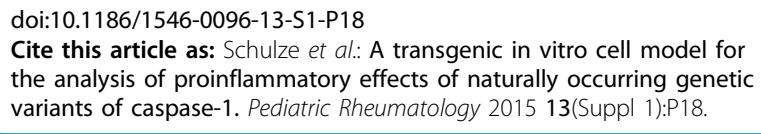

Submit your next manuscript to BioMed Central and take full advantage of:

- Convenient online submission

- Thorough peer review

- No space constraints or color figure charges

- Immediate publication on acceptance

- Inclusion in PubMed, CAS, Scopus and Google Scholar

- Research which is freely available for redistribution 